\title{
Correction to: Inheritance of the narrow leaf mutation in traditional Japanese evergreen azaleas
}

\author{
Keisuke Tasaki $\cdot$ Akira Nakatsuka $\cdot$ Kyeong-Seong Cheon $\cdot$ Nobuo Kobayashi
}

Published online: 26 March 2018

(C) Springer Science+Business Media B.V., part of Springer Nature 2018

Correction to: Euphytica (2015) 206:649-656

https://doi.org/10.1007/s10681-015-1479-z

This article has been published with an erroneous version of Table 2. Please find the correct Table 2 in this document.

The original article can be found online at https:// doi.org/10.1007/s10681-015-1479-z.

K. Tasaki

Department of Molecular and Functional Genomics, Center for Integrated Research in Science, Shimane University, Matsue, Shimane 690-8504, Japan

Present Address:

K. Tasaki Iwate Biotechnology Research Center, Narita, Kitakami, Iwate 024-0003, Japan

A. Nakatsuka · K.-S. Cheon · N. Kobayashi ( $\square)$ Faculty of Life and Environmental Sciences, Shimane University, Matsue, Shimane 690-8504, Japan

e-mail: nkobayashi@life.shimane-u.ac.jp 


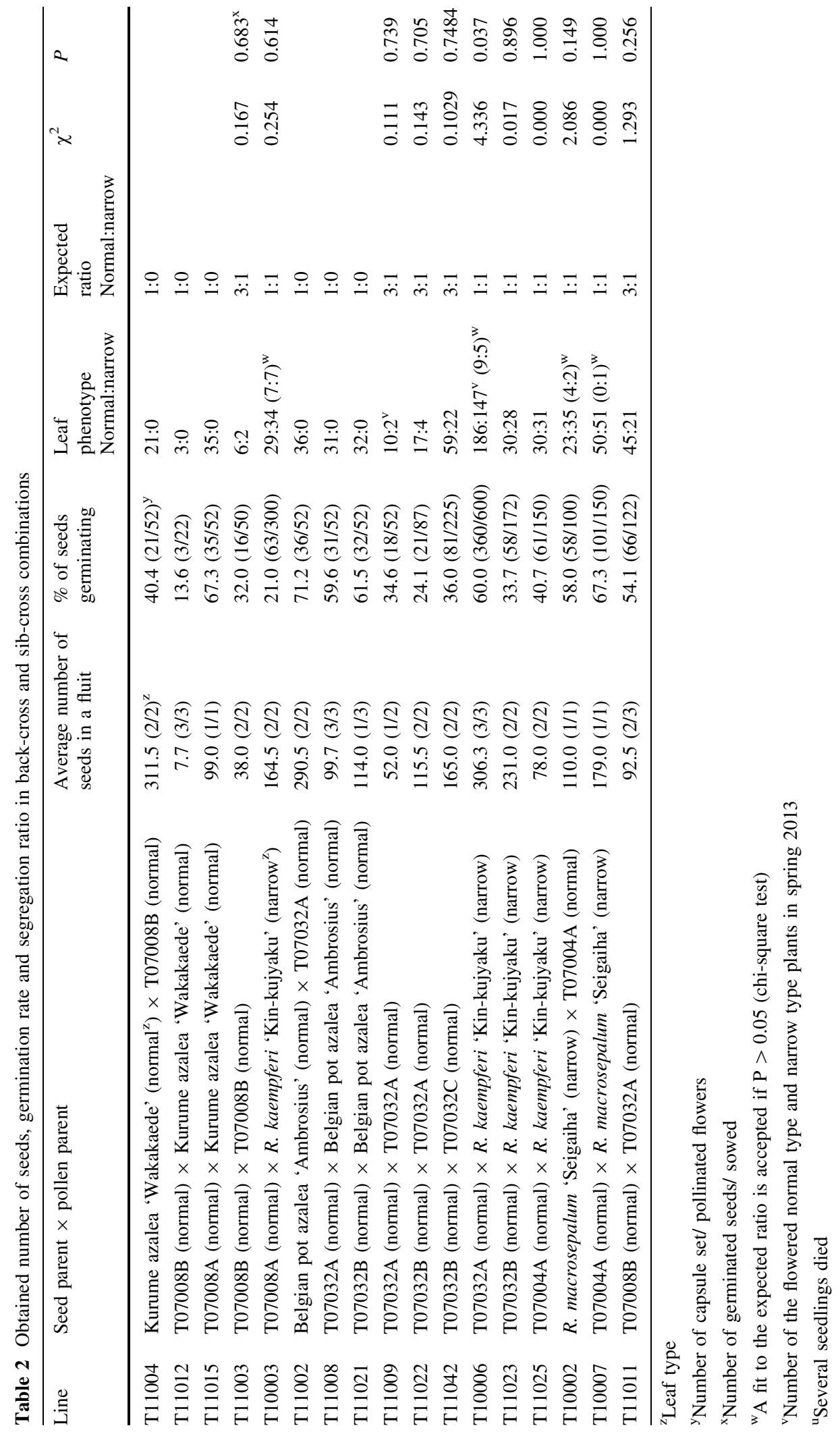

